\title{
Cardiac Myxomas: Clinical spectrum, investigation findings, and surgical treatment based on our 25-year-experiences
}

\author{
Trushar Gajjar, Nageswar Ra0, Neelam Desai \\ Sri Sathya Sai Institute of Higher Medical Sciences - Prasanthigram, CTVS Department, Prasanthigram, Andhra Pradesh, India
}

Received: August 15, 2016 Accepted: October 13, 2016 Published online: April 17, 2017

\begin{abstract}
Objectives: The aim of this study was to describe the clinical spectrum, investigation findings, and surgical treatment of cardiac myxomas. Patients and methods: Between November 1991 and July 2016, 229 patients (99 males, 130 females; mean age 37.1 years; range 7 to 63 years) with a primary or recurrent intra-cardiac myxoma underwent surgical excision at our institute. The diagnosis was made by transthoracic and transesophageal echocardiography. The basic surgical principle of complete wide excision was applied, and either unicameral (right or left atrial approach) or bicameral (both atria opened) surgical approach was used. Myxomas originating from the valve or valve annulus required a special attention. Postoperative echocardiograms were obtained in all patients before discharge. All patients were followed at three and 18 months, and five years postoperatively.

Results: The most common presenting symptoms were dyspnea and palpitation. There were 197 left atrial, 27 right atrial, two left ventricular, and one each of right ventricular, right ventricular outflow tract and multiple myxomas. There were three early death events; however no late mortality was seen. During follow-up, all patients were in the New York Heart Association Class I and echocardiography showed good ventricular functions with normal pulmonary artery pressure. Seven patients developed sporadic recurrence of myxoma. The valves were competent in the patients who underwent valve repair.

Conclusion: Based on our experience, we recommend the left atriotomy approach for left atrial myxomas and the right atriotomy approach for dumbbell-shaped left atrial and right atrial myxomas. Biatrial approach should be used in large and unusually located left atrial myxomas, while individualized approaches should be performed for others. To prevent recurrence, the surgical excision must include a substantial portion of normal endocardium near the base of implantation. The early mortality is commonly seen due to coronary embolism, and the late survival of patients after myxoma excision is usually excellent.
\end{abstract}

Keywords: Biatrial approach; cardiac tumor; left atrium; myxoma; recurrence.

Primary cardiac tumors are uncommon and represent only 5 to $10 \%$ of all neoplasms of the heart and pericardium. ${ }^{[1]}$ About $80 \%$ of primary cardiac tumors are benign and, of these, more than half are myxomas. $^{[2,3]}$ The incidence of cardiac myxomas is between 0.0013 to $0.005 \% .{ }^{[4]}$ The majority of the data originate from small series of patients in developed countries. In this article, we report our 25-year experiences and describe the clinical spectrum, investigation findings, and surgical treatment of cardiac myxomas.

\section{PATIENTS AND METHODS}

Between November 1991 and July 2016, a total of 229 patients (99 males, 130 females; mean age: 37.1 years; range, 7 to 63 years) underwent complete and wide excision of primary or recurrent intra-cardiac myxomas at our institute.

\section{Operative technique}

All patients were referred for surgery and conventional median sternotomy approach was used. The cardiopulmonary bypass was established by aortic and bicaval cannulation. The myocardial protection was achieved by antegrade root cardioplegia. A special care was taken to avoid a forceful manipulation of the heart before the aorta was cross-clamped. Various unicameral (either right or left atrial approach) or bicameral (both atria opened for big tumors, particularly for the left atrial tumors) approaches were used.

Corresponding author: Trushar Gajjar, MD. Sri Sathya Sai Institute of Higher Medical Sciences - Prasanthigram, CTVS Department, Prasanthigram, 515134 Andhra Pradesh, India.

Tel: +91 9700355411 e-mail: trushargajjar@gmail.com 


\section{Statistical analysis}

Statistical analysis was performed using SPSS version 10.0 software (SPSS Inc., Chicago, IL, USA). The Fisher's exact and chi-square tests were used to analyze statistical significance between variables. For continuous variables, the unpaired Student t-test was used. A $p$ value of less than 0.05 was considered statistically significant.

\section{RESULTS}

\section{Clinical findings}

The common presenting symptoms were dyspnea and palpitation. One patient who had a huge right atrial myxoma developed hypoxia and cyanosis due to rightto-left shunting through atrial septal defect. Detailed clinical presentation is described in the Table 1 . The laboratory findings showed an elevated erythrocyte sedimentation rate (ESR) in 171, anemia in 103,

\begin{tabular}{|c|c|c|}
\hline \multicolumn{3}{|c|}{$\begin{array}{c}\text { Table } 1 \\
\text { Clinical characteristics of patients }\end{array}$} \\
\hline & $\mathrm{n}$ & $\%$ \\
\hline \multicolumn{3}{|l|}{ Cardiac symptoms } \\
\hline Dyspnea & 199 & 86.9 \\
\hline Palpitation & 128 & 55.9 \\
\hline Chest pain & 64 & 27.9 \\
\hline Syncope & 46 & 20.1 \\
\hline $\begin{array}{l}\text { Orthopnea/paroxysmal nocturn } \\
\text { dyspnea }\end{array}$ & 12 & 5.2 \\
\hline Cyanosis & 1 & 0.4 \\
\hline \multicolumn{3}{|l|}{ Embolic symptoms } \\
\hline Central nervous system & 12 & 5.2 \\
\hline Peripheral & 1 & 0.4 \\
\hline Coronary & 1 & 0.4 \\
\hline \multicolumn{3}{|l|}{ Systemic symptoms } \\
\hline Fever & 54 & 23.6 \\
\hline Fatigue & 43 & 18.8 \\
\hline Weight loss & 32 & 14 \\
\hline \multicolumn{3}{|l|}{ Others } \\
\hline Pedal edema & 19 & 8.3 \\
\hline Miscelleneous & 9 & 3.9 \\
\hline \multicolumn{3}{|l|}{ Auscultation } \\
\hline Mid diastolic murmur & 153 & 66.8 \\
\hline Tumor plop & 114 & 49.8 \\
\hline Pansystolic murmur & 71 & 31.0 \\
\hline Loud pulmonary second sound & 62 & 27.1 \\
\hline \multicolumn{3}{|l|}{ Other signs } \\
\hline Edema & 9 & 3.9 \\
\hline Hepatomegaly & 7 & 3.1 \\
\hline Clubbing & 4 & 1.7 \\
\hline
\end{tabular}

eosinophilia in 55, elevated WBC count in 39 , and elevated serum globulin levels in all patients. A familial occurrence of the disease was excluded in the firstdegree relatives. Initial chest radiography showed cardiomegaly with a cardiothoracic ratio of 55 to $70 \%$, pulmonary congestion in 84 , and left atrial enlargement in 47 patients. Electrocardiography showed left atrial enlargement in 79 , right atrial enlargement in 21 , right axis deviation in 44 , left axis deviation in nine, right ventricular hypertrophy in 42 , left ventricular hypertrophy in 11, and right bundle branch block in 16 patients. Two-dimensional transthoracic and transesophageal echocardiography were done in all patients and was the main diagnostic tool (Figures 1,2). Of 229 patients, there were 197 left atrial, 27 right atrial, two left ventricular, and one each of right ventricular, right ventricular outflow tract, and multiple myxoma. These myxomas ranged from 3 to $16 \mathrm{~cm}$ in size at their greatest diameter. Preoperative right ventricular systolic pressure (RVSP) was less than $30 \mathrm{mmHg}$ in 29 patients, between 30 and $60 \mathrm{mmHg}$ in 55 patients, and higher than $60 \mathrm{mmHg}$ in 56 patients. In the remaining patients, RVSP was unable to be calculated. Mild right ventricular (RV) dysfunction was present in 10 patients, and moderate and severe RV dysfunction were seen in three and two patients, respectively. Isolated mild left ventricular (LV) dysfunction was present in two patients, while mild to moderate biventricular dysfunction was seen in three and global hypokinesia was detected in one patient. The remaining patients had good biventricular functions.

In addition, there were few associated lesions such as mild mitral regurgitation (MR) in 117 , moderate $M R$ in 21, severe MR in six, mild to moderate mitral stenosis in four, mild tricuspid regurgitation (TR) in 49, moderate TR in 10, severe TR in five and ostium secundum type of atrial septal defect (ASD-OS) in one patient. Coronary angiography was performed in patients above 40 years of age to rule out coronary artery lesions. One patient showed recanalized obtuse marginalis, while another patient had right coronary artery disease. In two patients, angiogram showed tumor blush from the right coronary artery and from the left coronary artery in another patient (Figure 3).

\section{Operative findings}

Complete excision of the tumor with a cuff of surrounding tissue was the basic principle of excision (Figures 4, 5a, b). Myxomas originating from the posterior mitral annulus required quadrangular 

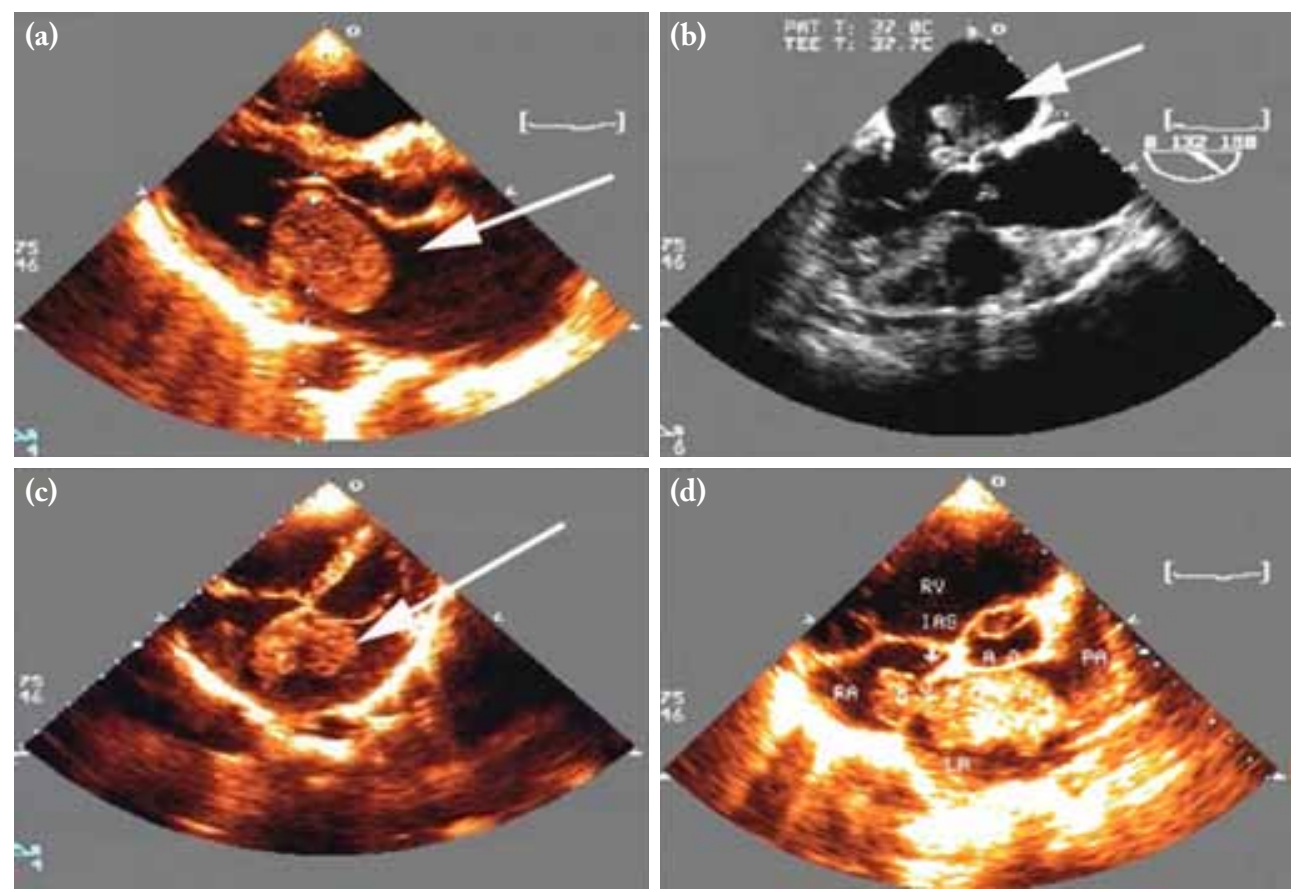

Figure 1. Transthoracic and transesophageal echocardiography images showing (a) a typical left atrial myxoma attached to the fossa ovalis of interatrial septum (arrow); (b) a multi-headed left atrial myxoma attached to the fossa ovalis of interatrial septum (arrow); (c) a left atrial myxoma attached to the interatrial septum and mitral valve-mimicking vegetation (arrow); and (d) a dumbbell-shaped myxoma, primarily in left atrium.

resection and prosthetic ring annuloplasty in six patients. Mitral valve repair was required in another 13 patients and repair was performed with anterior mitral leaflet chordal shortening and ring annuloplasty using prosthetic ring in seven patients and commissural annuloplasty in the remaining six patients. Myxomas arising from the tricuspid annulus were shaved off and modified DeVega's annuloplasty was done. In a patient with a myxoma arising from the right ventricular out flow tract involving the pulmonary valve leaflet required excision of the two leaflets. Details of surgical findings, approach, and technique are described in Table 2. Weaning from the cardiopulmonary bypass was done in a usual way. Transesophageal or epicardial echocardiography was done in the patients with valve regurgitation.
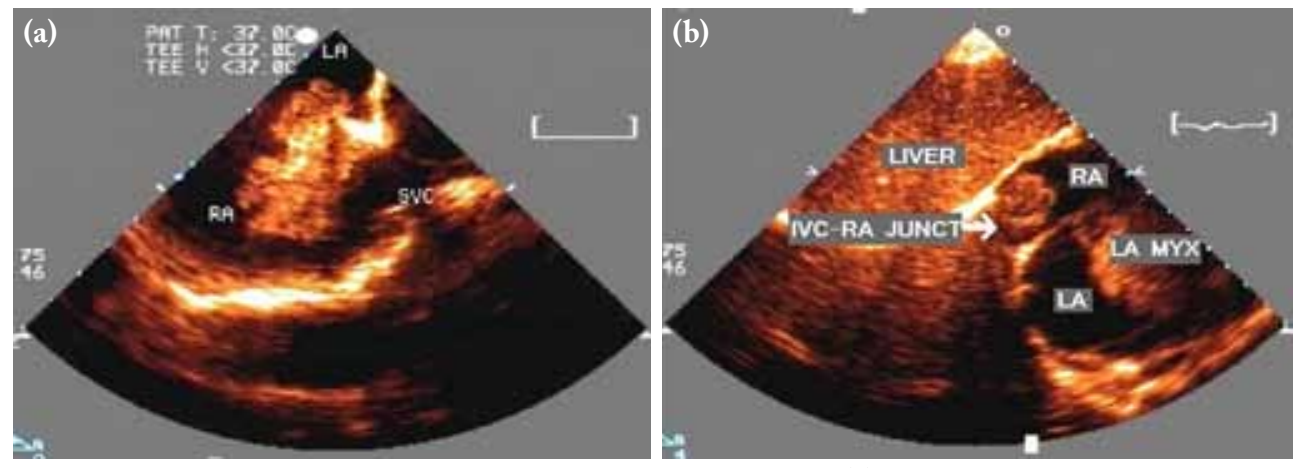

Figure 2. Transesophageal echocardiography images showing (a) a right atrial myxoma attached to the fossa ovalis of interatrial septum; and (b) a right atrial myxoma at inferior vena cava-right atrial junction. 

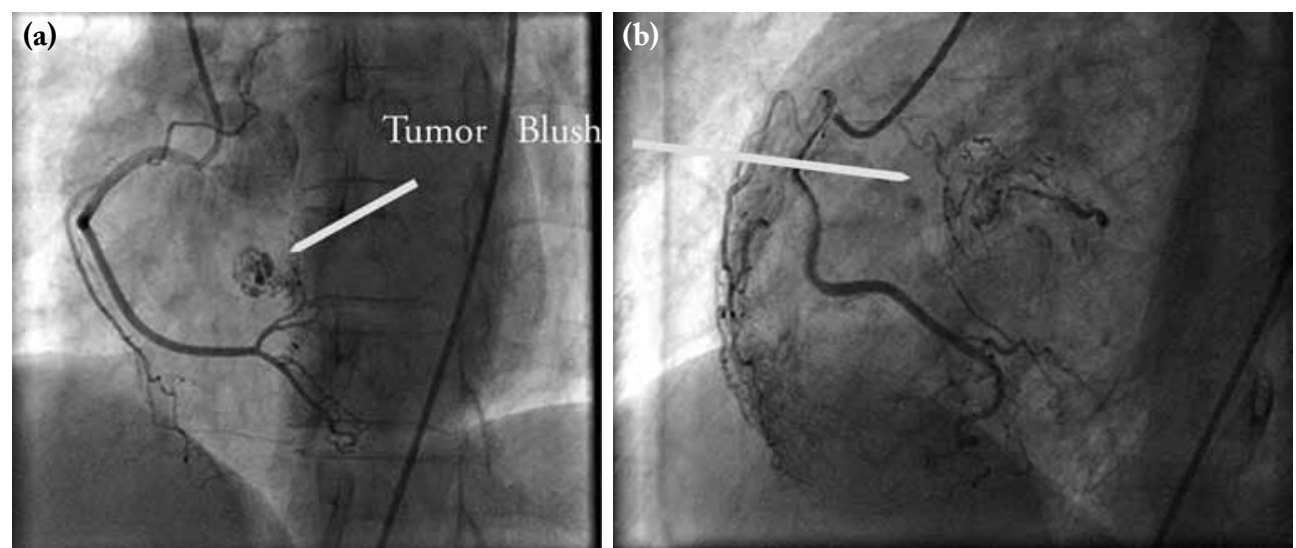

Figure 3. (a, b) A right-sided coronary angiogram showing tumor blush from right coronary artery (arrow).

\section{Postoperative outcomes}

There were three early mortalities in our entire series due to acute severe left ventricular dysfunction and multi-organ failure, probably secondary to coronary embolism. There was no late mortality. One patient developed convulsion postoperatively and cranial computed tomography (CT) showed an old parietal lobe infarct. The patient was recovered and discharged uneventfully. One patient also developed cerebral hypoxia due to cyanosis caused by right-to-left shunting across the ASD, secondary to right atrial outflow obstruction caused by a huge right atrial myxoma. The patient required prolonged ventilation; however, he recovered and was uneventfully discharged. All patients underwent transthoracic echocardiography on the day of surgery in the intensive care unit and before discharge to evaluate the ventricular functions, valve repair status, and possibility of residual tumors. Echocardiography revealed no residual myxoma in all patients $(n=229)$, good biventricular functions in 224 patients, mild to moderate right ventricular dysfunction in two patients, and severe left ventricular dysfunction in three patients. Three patients also developed mild to moderate $\mathrm{MR}$, one patient developed severe MR requiring mitral valve repair, and one patient developed severe TR, which was medically managed. Postoperatively, the right ventricular systolic pressure was less than $30 \mathrm{mmHg}$ in 87 patients, between 30 and $60 \mathrm{mmHg}$ in 41 patients, and higher than $60 \mathrm{mmHg}$ in two patients. None of the patients had pulmonary embolism. The mean length of intensive care unit stay was 6 (range: 2 to 9) days and the mean length of hospital stay was 9 (range: 5 to 18 ) days. Follow-up was done at three months, one and five years, and 6 to 17 years. A total of 226 patients survived after the operation, and 203 of them (90\%) attended to follow-up at three months. However, the remaining 23 patients (10\%) were lost to follow-up. Of the patients, $40.3 \%(n=66)$ attended to the followup at one year, $30.5 \%(n=69)$ at five years, and $24.3 \%$ $(\mathrm{n}=55)$ between 5 to 17 years. All patients were in the New York Heart Association (NYHA) Class I and echocardiography showed that all patients had good ventricular functions with normal pulmonary artery pressures. However, there were six patients with moderate $M R$, one with severe $M R$, and two with moderate to severe TR during follow-up. One patient developed right parietal area infarct leading to left hemiparesis. The patient with severe mitral regurgitation was advised mitral valve replacement. There were seven patients with a recurrent myxoma (Figure $5 \mathrm{c}$ ) in our entire series, and the mean time to recurrence was 7.2 (range: 2 to 13) years. Apart from one case of multiple myxomas, the remaining six patients developed recurrence at the same site or adjacent area, probably due to inadequate excision or tumor sidling. In a patient with multiple myxomas, a left ventricular myxoma which was developed was thought to be due to multi-centric foci. The location at the initial surgery, recurrence period and site of recurrence are described in Table 3.

\section{DISCUSSION}

Although primary tumors of the heart are rare, myxomas are the most frequent benign primary heart 

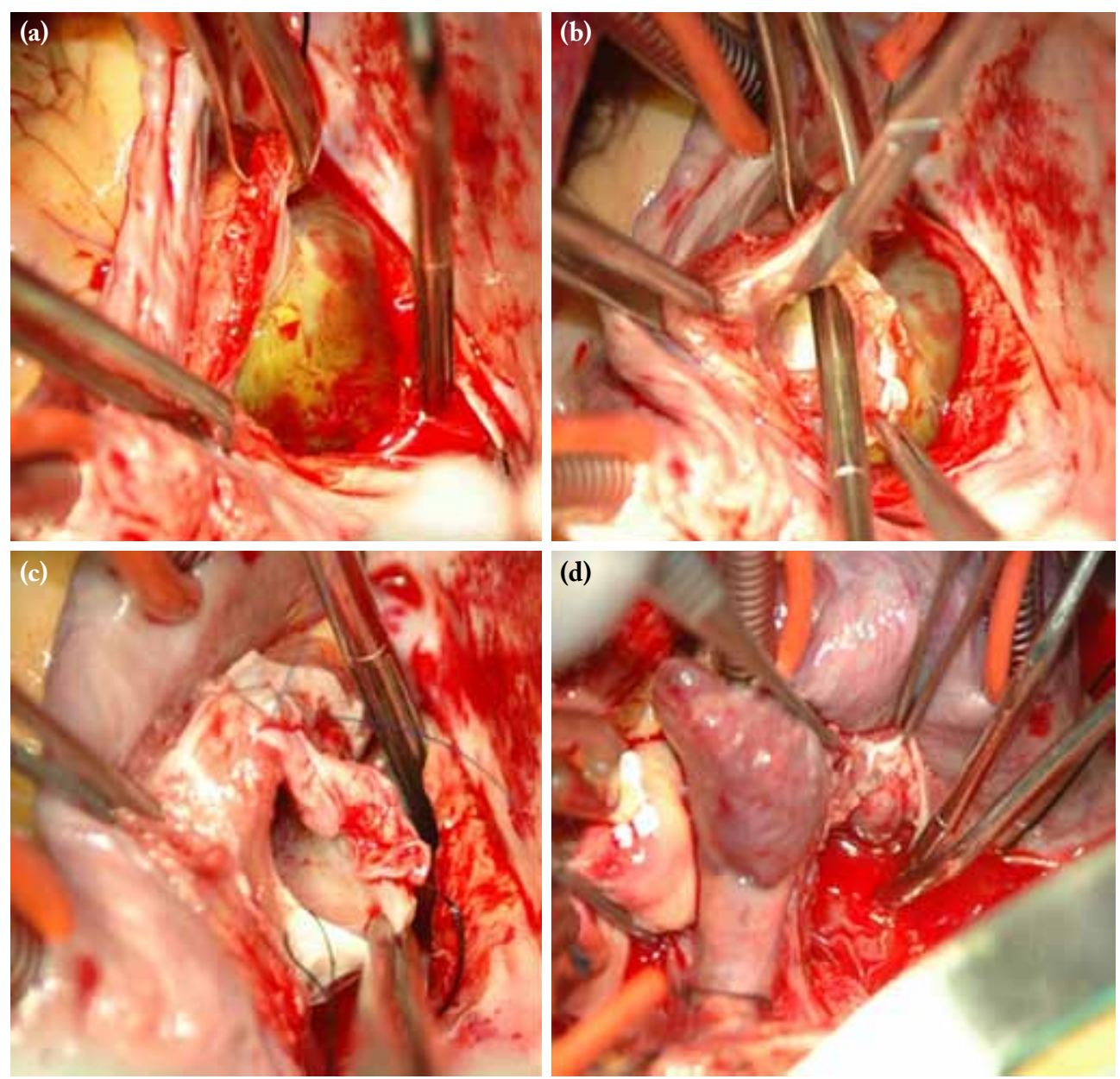

Figure 4. An intraoperative view of left atrial myxoma excision through left atriotomy approach. (a) Left atrial approach showing myxoma attached to the interatrial septum; (b) left atrial myxoma along with interatrial septum excised; (c) a septal defect closure using an autologous untreated pericardial patch; and (d) a completed septal closure and checking for suture line leakage.

tumors, which account for $0.3 \%$ of open heart surgery worldwide. The clinical presentation in the majority of the patients includes significant hemodynamic symptoms related to the blood flow obstruction and embolic phenomena. Cardiac myxomas can be challenging to diagnose, due to their rare occurrence and varying clinical presentation. The mean age was 37.1 years at the time of diagnosis in our study,
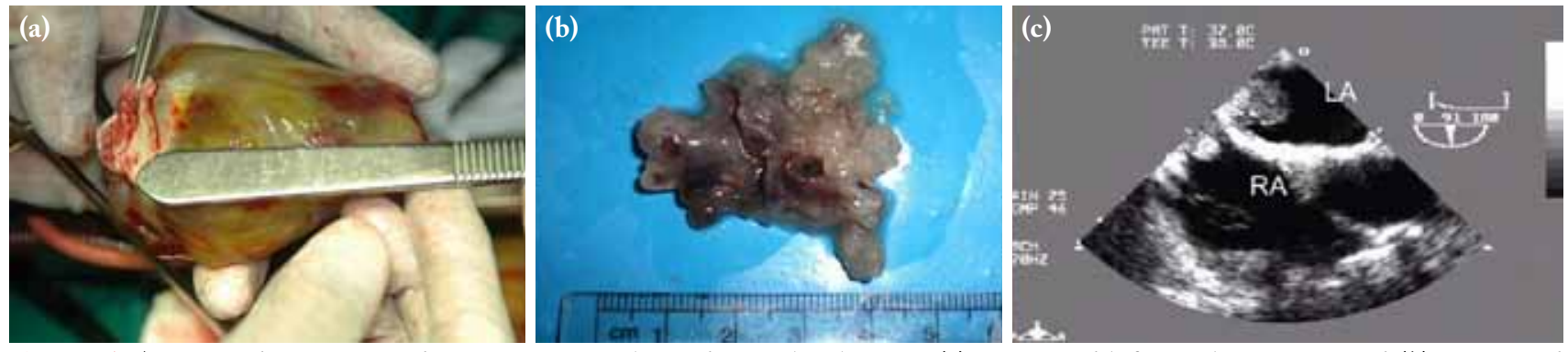

Figure 5. An excised myxoma and postoperative echocardiography showing (a) an excised left atrial myxoma; and (b) an excised multi-headed myxoma. (c) Postoperative transesophageal echocardiography showing a recurrent biatrial myxoma. 


\begin{tabular}{|c|c|c|c|c|c|c|c|c|}
\hline \multicolumn{9}{|c|}{$\begin{array}{c}\text { Table } 2 \\
\text { d approache }\end{array}$} \\
\hline LA myxoma & & & RA myxoma & & & Others & & \\
\hline Site of attachment & $\mathrm{n}$ & $\%$ & Site of attachment & $\mathrm{n}$ & $\%$ & Site of attachment & $\mathrm{n}$ & $\%$ \\
\hline Fossa ovalis (IAS) & 170 & 86.3 & Fossa ovalis & 23 & 85.2 & LV apex & 2 & 50 \\
\hline LA roof & 17 & 6.6 & IVC-RA junction & 3 & 11 & RV-IVS & 1 & 25 \\
\hline PML annulus & 6 & 3.0 & Tricuspid annulus & 1 & 3.7 & $\begin{array}{l}\text { Conal septum \& PV } \\
\text { cusps }\end{array}$ & 1 & 25 \\
\hline Pulmonary veins & 3 & 1.3 & & & & LA, RA, RVOT & 1 & 25 \\
\hline Base of LAA & 1 & 0.5 & & & & & & \\
\hline Approach & & & Approach & & & Approach & & \\
\hline LA & 145 & 73.6 & RA & 27 & 100 & LA \& aortic & 2 & 50 \\
\hline RA & 27 & 13.7 & & & & RA \& PA & 2 & 50 \\
\hline Biatrial & 25 & 12.7 & & & & PA & 1 & 25 \\
\hline Technique & & & Technique & & & Technique & & \\
\hline $\mathrm{WE}+$ direct closure & 155 & 58.4 & $\begin{array}{c}\mathrm{WE}+\text { pericardial patch } \\
\text { closure }\end{array}$ & 23 & 85.2 & WE & 3 & 75 \\
\hline $\begin{array}{l}\text { WE + pericardial } \\
\text { patch closure }\end{array}$ & 57 & 28.9 & Excision \& fulguration & 4 & 14.8 & $\begin{array}{c}\mathrm{WE}+\text { pericardial patch } \\
\text { closure }\end{array}$ & 1 & 25 \\
\hline Excision \& fulguration & 23 & 11.7 & & & & & & \\
\hline $\begin{array}{l}\text { WE + Dacron patch } \\
\text { closure }\end{array}$ & 2 & 1.0 & & & & & & \\
\hline Additional procedures & & & Additional procedures & & & Additional procedures & & \\
\hline Mitral annuloplasty & 19 & 9.6 & Tricuspid annuloplasty & 10 & 37.0 & Pulmonary valvectomy & 1 & 25 \\
\hline $\begin{array}{l}\text { CABG \& mitral } \\
\text { annuloplasty }\end{array}$ & 1 & 0.5 & & & & & & \\
\hline
\end{tabular}

which is significantly lower than in most Western countries where the mean age is 50 to 55 years. ${ }^{[5-7]} \mathrm{In}$ addition, dyspnea was the most common symptom in our patients as the obstructive pathology. Patients may also present with cyanosis and cerebral hypoxia produced by right-to-left shunting secondary to the right ventricular inflow obstruction caused by a huge right atrial myxoma associated with patent foramen ovale or ASD, as in one of our patients. A higher risk of embolization has been also reported and events occur in 30 to $45 \%$ of the patients. ${ }^{[5-10]}$ In our series, the embolization was less

\begin{tabular}{lcc} 
& \multicolumn{1}{c}{$\begin{array}{c}\text { Table } 3 \\
\text { Recurrence data }\end{array}$} & Site of recurrence \\
\hline Location at first surgery & Recurrence period (years) & Biatrial (IAS) \\
Right atrium (IAS, fossa ovalis) & 13 & Biatrial \& extending to right atrium wall \\
Left atrium (IAS) & 13 & LA (IAS) \\
Right atrium (Lower end of fossa ovalis) & 9 & RA (IAS) \\
Left atrium (IAS) & 7 & Left ventricle apex \\
Multiple (LA, RA, RVOT) IAS \& RVOT & 5 & Biatrial (IAS) \\
Left atrium (IAS) & 2 & 2 \\
Biatrial (IAS) & 2 & IAS \\
IAS: Interatrial septum; LA: Left atrium; RA: Right atrium; RVOT: Right ventricular outflow tract.
\end{tabular}


frequent than the Western series. In our series a total of 14 patients developed embolization preoperatively and three patients developed tumor embolization postoperatively. Of 14 patients, 12 patients had central nervous system (CNS) embolization and one each had peripheral arterial and coronary artery embolization. Of three patients with postoperative tumor embolization, two developed in the early postoperative period and one patient developed in the late postoperative period. All these patients had CNS embolization. Anemia and elevated ESR are non-specific markers of several diseases and are significantly more common in our study. The presence of systemic symptoms was positively correlated with elevated ESR. Systemic symptoms, anemia, and elevated ESR could be due to the systemic effects of interlukin-6, the cytokine implanted in generating a generalized inflammatory response in patients with myxomas. There were also elevated serum globulin levels in all patients with reversal of albuminglobulin ratio in our series.

Echocardiography is currently the most main diagnostic modality available for imaging cardiac tumors. It is non-invasive and allows a preoperative diagnosis with accuracy and can quantitate the tumor size, shape, attachment, and mobility. ${ }^{[11,12]}$ It can also screen the other chambers of the heart for additional tumors. In addition, transesophageal echocardiography has an increased sensitivity and specificity for the diagnosis, particularly in patients with poor transthoracic echo window. ${ }^{[11,12]}$ In our series, the two-dimensional transthoracic and transesophageal echocardiography were successful primary tools for the diagnosis of cardiac tumors. Magnetic resonance imaging (MRI) and CT are not the first-line diagnostic tools for myxomas, although more and more cases are diagnosed by these technologies. These modalities are helpful to detect benign and malignant tumors, when transthoracic and transesophageal echocardiography offer limited tissue characterization and confident distinction between thrombi. ${ }^{[11-14]}$ In addition, prolapse through the mitral valve orifice on $\mathrm{CT}$ is a reliable discriminative finding indicating a myxoma, ${ }^{[11-14]}$ while the absence of both first-pass and delayed contrast enhancement on MRI is suggestive of a thrombus. ${ }^{[11-14]}$

Cardiac CT is also useful to detect metastases in suspected malignancies, particularly when coupled with 18 F-fluorodeoxyglucose (FDG) positron emission tomography (PET). However, if a mass has a typical echocardiographic appearance and is located as a left atrial myxoma, additional images with $\mathrm{CT}$ or MRI are unnecessary. Surgical excision is the treatment and must be undertaken immediately to avoid the complications, such as systemic embolization and valvular obstruction or incompetence.

The first successful surgery of a myxoma was performed by Crafoord in Stockholm, Sweden in 1955, on cardiopulmonary bypass. ${ }^{[1-19]}$ Since then, many approaches have been described in the literature, such as left atriotomy, right atriotomy and biatrial approach. ${ }^{[11-19]}$ In our series, the approaches used for left atrial myxomas are left atriotomy in $73.6 \%$ ( $\mathrm{n}=145)$, right atriotomy in $13.7 \%(\mathrm{n}=27)$, and biatrial approach in $12.7 \%$ patients $(n=25)$. Based on our findings, we found that the left atriotomy approach was much more convenient, simple, rapid, and safe approach for the excision of the left atrial myxomas. The right atriotomy approach was used for dumbbell-shaped left atrial myxomas. The biatrial approach was used in large and unusually located left atrial myxomas. The right atrial myxoma was approached through right atriotomy, while other types of myxoma were approached either through right atrium and pulmonary artery for the right ventricular outflow tract myxomas and left atriotomy and transaortic approach for the left ventricular myxomas. A wide excision with direct closure of the defect was also done in $58.4 \%$, pericardial patch closure of the defect in $28.9 \%$, excision and fulguration of the raw area in $11.7 \%$, and the use of a Dacron patch in 1\% patients of left atrial myxomas. For the right atrial myxoma excision, a pericardial patch was used in $85.2 \%$ patients and excision with fulguration was done in $14.8 \%$ patients. Myxomas attached to the chamber wall apart from the interatrial septum, such as the right ventricular septum, left ventricular apex, and tricuspid valve annulus require wide excision alone or excision with fulguration. Myxomas attached to the pulmonary valve require excision of the valve leaflet, while those attached to the posterior mitral leaflet can be excised with the quadrangular resection of the leaflet with myxoma, followed by prosthetic ring annuloplasty. Myxomas attached to the anterior mitral leaflet require treatment according to the involvement of the leaflet area. If a small portion of the leaflet is involved, myxoma can be shaved off the leaflet, or a small portion of the leaflet can be excised, and the defect can be repaired with an autologous pericardial patch. However, if the major portion of the leaflet is involved, it may require mitral valve replacement. To prevent recurrence, there 
is a consensus that surgical excision must include a substantial portion of the normal endocardium near the base of implantation. ${ }^{[16-19]}$ Recurrence can be due to inadequate resection, intraoperative implantation, embolization or multi-centric growth. ${ }^{[5,6]}$ In our series, the recurrence rate was $3.1 \%$, which is comparable to the international standard of $5 \% \cdot{ }^{[16,17,19]}$ The recurrence was mainly found in left atrial myxomas, excised through right atriotomy approach, probably due to inadequate excision or intraoperative implantation. In one case of multiple myxomas, recurrence was seen at a different location, probably due to the multi-centric growth. There were also three early mortalities in our entire series, due to acute severe left ventricular dysfunction and multi-organ failure, probably secondary to coronary embolism. There was no late mortality or pulmonary embolism.

In conclusion, cardiac myxomas are the most common benign cardiac tumors in adults and the left atrium is the commonest chamber involved. Transthoracic and transesophageal echocardiography is the optimal diagnostic modalities for myxomas. The diagnosis of a cardiac myxoma is an indication for an urgent surgery, due to the high risk of sudden death from a thromboembolism or valvular obstruction. Therefore, we recommend the left atriotomy approach for the left atrial myxoma excision in view of convenience, simplicity, and safety and right atriotomy approach for dumbbell-shaped and right atrial myxomas. The biatrial approach can be used in large and unusually located left atrial myxomas, while individualized approaches can be used for the treatment of for other types of myxoma. To prevent recurrence, the surgical excision must include a substantial portion of the normal endocardium near the base of implantation. The early mortality is most commonly due to coronary embolism and the late postoperative survival is usually excellent.

\section{Declaration of conflicting interests}

The authors declared no conflicts of interest with respect to the authorship and/or publication of this article.

\section{Funding}

The authors received no financial support for the research and/or authorship of this article.

\section{REFERENCES}

1. Prichard RW. Tumors of the heart; review of the subject and report of 150 cases. AMA Arch Pathol 1951;51:98-128.
2. Gerbode F, Kerth WJ, Hill JD. Surgical management of tumors of the heart. Surgery 1967;61:94-101.

3. Bhan A, Mehrotra R, Choudhary SK, Sharma R, Prabhakar D, Airan B, et al. Surgical experience with intracardiac myxomas: long-term follow-up. Ann Thorac Surg 1998;66:810-3.

4. Reece IJ, Cooley DA, Frazier OH, Hallman GL, Powers PL, Montero CG. Cardiac tumors. Clinical spectrum and prognosis of lesions other than classical benign myxoma in 20 patients. J Thorac Cardiovasc Surg 1984;88:439-46.

5. Pinede L, Duhaut P, Loire R. Clinical presentation of left atrial cardiac myxoma. A series of 112 consecutive cases. Medicine (Baltimore) 2001;80:159-72.

6. Burke AP, Virmani R. Cardiac myxoma. A clinicopathologic study. Am J Clin Pathol 1993;100:671-80.

7. Bjessmo S, Ivert T. Cardiac myxoma: 40 years' experience in 63 patients. Ann Thorac Surg 1997;63:697-700.

8. Pucci A, Gagliardotto P, Zanini C, Pansini S, di Summa M, Mollo F. Histopathologic and clinical characterization of cardiac myxoma: review of 53 cases from a single institution. Am Heart J 2000;140:134-8.

9. Alvarez-Sabín J, Lozano M, Sastre-Garriga J, Montoyo J, Murtra M, Abilleira S, et al. Transient ischaemic attack: a common initial manifestation of cardiac myxomas. Eur Neurol 2001;45:165-70.

10. O'Rourke F, Dean N, Mouradian MS, Akhtar N, Shuaib A. Atrial myxoma as a cause of stroke: case report and discussion. CMAJ 2003;169:1049-51.

11. Read RC. Cardiac myxoma and surgical history. Ann Thorac Surg 1980;29:395-6.

12. Read RC, White HJ, Murphy ML, Williams D, Sun CN, Flanagan WH. The malignant potentiality of left atrial myxoma. J Thorac Cardiovasc Surg 1974;68:857-68.

13. Sparrow PJ, Kurian JB, Jones TR, Sivananthan MU. MR imaging of cardiac tumors. Radiographics 2005;25:1255-76.

14. Scheffel H, Baumueller S, Stolzmann P, Leschka S, Plass A, Alkadhi $\mathrm{H}$, et al. Atrial myxomas and thrombi: comparison of imaging features on CT. AJR Am J Roentgenol 2009;192:639-45.

15. O'Donnell DH, Abbara S, Chaithiraphan V, Yared K, Killeen RP, Cury RC, et al. Cardiac tumors: optimal cardiac MR sequences and spectrum of imaging appearances. AJR Am J Roentgenol 2009;193:377-87.

16. Jones DR, Warden HE, Murray GF, Hill RC, Graeber GM, Cruzzavala JL, et al. Biatrial approach to cardiac myxomas: a 30-year clinical experience. Ann Thorac Sur 1995;59:851-5.

17. Murphy MC, Sweeney MS, Putnam JB Jr, Walker WE, Frazier $\mathrm{OH}$, Ott DA, et al. Surgical treatment of cardiac tumors: a 25-year experience. Ann Thorac Surg 1990;49:612-7.

18. Reece IJ, Cooley DA, Frazier OH, Hallman GL, Powers PL, Montero CG. Cardiac tumors. Clinical spectrum and prognosis of lesions other than classical benign myxoma in 20 patients. J Thorac Cardiovasc Surg 1984;88:439-46.

19. Jain S, Maleszewski JJ, Stephenson CR, Klarich KW. Current diagnosis and management of cardiac myxomas. Expert Rev Cardiovasc Ther 2015;13:369-75. 